\title{
Quasi-biennial oscillation influence on long-period planetary waves in the Antarctic upper mesosphere
}

\author{
R. E. Hibbins, ${ }^{1}$ M. J. Jarvis, ${ }^{1}$ and E. A. K. Ford ${ }^{1}$ \\ Received 19 September 2008; revised 2 March 2009; accepted 5 March 2009; published 14 May 2009.
}

[1] Long-period planetary wave data derived from meteor wind observations recorded over a 12-year period with the SuperDARN radar at Halley, Antarctica, are presented and compared with the phase of the quasi-biennial oscillation (QBO) throughout the equatorial stratosphere. Enhanced planetary wave activity in the Antarctic upper mesosphere is found during the summer months, when the QBO in the equatorial upper stratosphere is westerly, and during the late winter, when the QBO in the upper stratosphere is easterly. These quasi-biennial enhancements in planetary wave activity coincide with a reduction in strength, by up to $30 \%$, of the late-winter eastward winds in the Antarctic upper mesosphere. In addition, when the QBO is in the correct phase for enhanced planetary wave activity in the upper mesosphere above Halley, planetary wave activity measured in the upper mesosphere of the high-latitude Northern Hemisphere is reduced (and vice versa). These results clearly indicate significant interhemispheric propagation of planetary waves from the winter to summer hemispheres. Observational evidence that the stratospheric QBO induces a strong enough QBO in the equatorial upper mesosphere to act as a gate to the interhemispheric propagation of these long-period waves is discussed in light of these results.

Citation: Hibbins, R. E., M. J. Jarvis, and E. A. K. Ford (2009), Quasi-biennial oscillation influence on long-period planetary waves in the Antarctic upper mesosphere, J. Geophys. Res., 114, D09109, doi:10.1029/2008JD011174.

\section{Introduction}

[2] In the equatorial stratosphere, a pronounced quasibiennial oscillation (QBO) exists in the mean zonal wind with cycles between $\sim 22$ and $\sim 34$ months [e.g., Naujokat, 1986]. Previous studies investigating the influence of the equatorial stratospheric QBO in the extratropical mesosphere and lower thermosphere (MLT) region have included observations of the mean winds, tides and planetary waves. Namboothiri et al. [1993, 1994] used MF radar data from Saskatoon, Canada $\left(52^{\circ} \mathrm{N}, 107^{\circ} \mathrm{W}\right)$ recorded over a solar cycle to search for variability in the mean winds in the MLT region. They observed a biennial periodicity in the yearround zonal winds, and used least squares fits to 26-month periodic oscillations to demonstrate a clear QBO in the horizontal wind pattern at certain mesospheric heights. Namboothiri et al. [1999] observed a biennial periodicity in the duration of the summertime westward jet at $70-75 \mathrm{~km}$ altitude using VHF radar data from Shigaraki, Japan $\left(35^{\circ} \mathrm{N}\right.$, $\left.136^{\circ} \mathrm{E}\right)$. When the QBO at $40-50 \mathrm{hPa}$ was westerly the summertime jet was found to last for around one month longer than during the easterly phase of the QBO.

[3] Espy et al. [1997], using airglow emissions from the $\sim 8 \mathrm{~km}$ thick hydroxyl layer centered near $87 \mathrm{~km}$ to measure $\mathrm{OH}^{*}$ rotational temperatures, derived summertime planetary wave data from neutral mesospheric temperatures

${ }^{1}$ Physical Sciences Division, British Antarctic Survey, Cambridge, UK.

Copyright 2009 by the American Geophysical Union. 0148-0227/09/2008JD011174 at Stockholm, Sweden $\left(59^{\circ} \mathrm{N}, 18^{\circ} \mathrm{E}\right)$ between 1992 and 1995. They found that a strong summertime 16-day wave was present in the data during the two summers when the QBO around $10 \mathrm{hPa}$ was in the westerly phase, and no significant 16-day wave activity when the QBO was easterly. This was presented as strong evidence for interhemispheric meridional propagation of the 16-day wave, generated in the winter (Southern) hemisphere.

[4] However, Jacobi et al. [1998] looked at the inter annual variability of waves with periods between 2 and 18 days from 13 years of mesopause region horizontal winds recorded with an LF radar situated at Collm, Germany $\left(52^{\circ} \mathrm{N}, 15^{\circ} \mathrm{E}\right)$. They found a weak dependence between the summertime 16-day wave and the QBO but correlation analysis did not prove statistical significance. Similarly, Mitchell et al. [1999] did not see any clear evidence for QBO modulation of the 16 day wave recorded over 4 years with a meteor radar located at Sheffield, UK $\left(54^{\circ} \mathrm{N}, 2^{\circ} \mathrm{W}\right)$. Luo et al. [2000] found a weak QBO modulation in both the summer and wintertime MLT 16-day wave derived from 17 years of MF radar data from Saskatoon, Canada, and a strong burst of 16-day wave activity in the summer of 1995 at an altitude of $79-85 \mathrm{~km}$ from data derived from MF radars located at both Saskatoon $\left(52^{\circ} \mathrm{N}, 107^{\circ} \mathrm{W}\right)$ and London, Canada $\left(43^{\circ} \mathrm{N}, 81^{\circ} \mathrm{W}\right)$ during a westerly phase of the QBO [Luo et al., 2002a]. Höppner and Bittner [2007] used nightly mean $\mathrm{OH}^{*}(3,1)$ rotational temperatures, representative of the temperature around $87 \mathrm{~km}$, from Wuppertal, Germany $\left(51^{\circ} \mathrm{N}, 7^{\circ} \mathrm{E}\right)$ between 1980 and 2005 . By comparing the strength of planetary waves in the range 3-20 days 
recorded in adjacent years they demonstrated a tendency for increased wintertime planetary wave activity during periods when the QBO at $30 \mathrm{hPa}$ reverses from a westerly to easterly phase. The quasi-2-year modulation was seen most strongly in their data around the maximum of the Hale cycle of solar bipolar magnetic field during 1994-5 with corresponding minima around 1988 and 2004.

[5] In the Southern Hemisphere high-latitude MLT region, observations have been less extensive. Jarvis [1996] used 37 years of geomagnetic data from Faraday research station $\left(65^{\circ} \mathrm{S}, 64^{\circ} \mathrm{W}\right)$ to derive semidiurnal tides in the dynamo region $(100-140 \mathrm{~km})$ from the $\mathrm{Sq}$ variation in the $\mathrm{H}$ component of the geomagnetic field measured on the ground. The Sq range is the daily cycling of the horizontal component during geomagnetically quiet conditions as a consequence of the daily variation of the ionospheric conductivity and lower thermospheric tidal motions. Periodogram analysis of the tidal amplitudes revealed a modulation with a period of 27 months, significant at the $98 \%$ level. Extension of this study globally revealed that this modulation of the semidiurnal tide in the lower thermosphere peaked at latitudes around $60^{\circ}$ [Jarvis, 1997]. Baumgaertner et al. [2005] found no clear evidence for a QBO modulation of either the mean winds or tides between 75 and $95 \mathrm{~km}$ altitude recorded over a 25-year period with the Scott Base $\left(78^{\circ} \mathrm{S}, 167^{\circ} \mathrm{E}\right) \mathrm{MF}$ radar. However, Hibbins et al. [2007] presented data showing a QBO-like modulation of the Antarctic semidiurnal tide recorded at meteor heights above Halley, Antarctica $\left(76^{\circ} \mathrm{S}, 27^{\circ} \mathrm{W}\right)$ based on 11 years of SuperDARN radar observations between 1996 and 2007. When the QBO above $\sim 20 \mathrm{hPa}$ was in a westerly phase an enhancement in the amplitude of the summertime semidiurnal tide by up to $4 \mathrm{~ms}^{-1}$ was seen. Thus, there is mixed evidence regarding the influence of the QBO on MLT dynamics in the Antarctic region. While a QBO influence has been indicated in the lower thermosphere in the South Atlantic sector of the Antarctic, there has been no clear evidence in the South Pacific sector. This may, in part, be the consequence of processes where the source of variability is not local; Hibbins et al. [2007], for instance, have suggested the influence of QBO-modulated planetary wave propagation. Here we use meteor radar horizontal wind data, recorded over a 12-year period, with the highest geographic latitude Southern Hemisphere SuperDARN radar which is located at Halley, Antarctica. We present evidence for a quasi-biennial modulation of the long-period planetary wavefield and zonal mean wind in both the summer and late winter Antarctic MLT. For comparison between hemispheres we also present similar data recorded from the Northern Hemisphere high-latitude SuperDARN radar located at Pykkvibær, northern Iceland $\left(64^{\circ} \mathrm{N}, 19^{\circ} \mathrm{W}\right)$, and discuss the possible role of the mesospheric QBO in modulating the interhemispheric propagation of planetary waves at MLT heights.

\section{Data}

[6] The Halley SuperDARN radar [Greenwald et al., 1985, 1995] has been operating since 1988 primarily recording $F$ region convection utilizing coherent scatter from plasma irregularities in the ionosphere. Echoes recorded by these radars in the first few range gates (the distance bin from the radar, from the time delay from the signal transmission, i.e., nearest the radar) have been shown to be due to the ionisation trail left by meteors as they ablate in the upper mesosphere and lower thermosphere [Hall et al., 1997; Jenkins and Jarvis, 1999; Hussey et al., 2000; Yukimatu and Tsutsumi, 2002]. Tracing the evolution of these trails provides an estimate of the neutral wind averaged over meteor ablation altitudes of around $80-100 \mathrm{~km}$ [Hocking et al., 2001]. Zonal and meridional hourly mean horizontal winds were derived by singular value decomposition [Press et al., 1992] of the spatial distribution of the radial velocities of all echoes with a signal to noise greater than $3 \mathrm{~dB}$. Signals used were returned from the first five range gates (the distance bins into which the radar data are sorted, derived from the signal time delay), between 180 and $405 \mathrm{~km}$ from the radar, assuming a scattering height of $95 \mathrm{~km}$. Line of sight velocities greater than $100 \mathrm{~ms}^{-1}$, or with an error greater than $50 \mathrm{~ms}^{-1}$, or a spectral width greater than $25 \mathrm{~ms}^{-1}$, were excluded from the fitting. An hourly fit was only attempted if echoes were recorded in at least five different radar beams.

[7] Data recorded between January 1996 and December 2007 were included in this study, during which the SuperDARN radar at Halley was sounding above $12 \mathrm{MHz}$ for $85 \%$ of the time and between 10 and $12 \mathrm{MHz}$ for $15 \%$ of the time. Hibbins and Jarvis [2008] have shown that the mean winds and semidiurnal tide observed from the Halley SuperDARN radar data are in good agreement with the data recorded in the 90-95 km height bin of a colocated imaging Doppler interferometer [Jones et al., 1997], and the mean location of the scattering points used in determining the SuperDARN winds is $78^{\circ} \mathrm{S}, 24^{\circ} \mathrm{W}$.

[8] The hourly mean data were averaged into daily means provided at least 8 different hours of data were available in that day. The data were then band-pass filtered using a Lanczos filter with 50 weights [e.g., Jacobi et al., 2007] between periods of 12 and 30 days. Missing days in the time series (occurring for less than $8 \%$ of the total 12 years of operation) were padded prior to filtering with a normal distribution of white noise with a standard deviation equal to that of the filtered data, and thereafter excluded from the analysis.

[9] In addition, meteor wind data recorded between January 1996 and December 2006 from the Northern Hemisphere high-latitude SuperDARN radar located at Pykkvibær, northern Iceland [Milan et al., 1997] were treated in exactly the same way as for the Halley data. Here, daily data coverage was $\sim 93 \%$ and the mean location of the scattering points was $66^{\circ} \mathrm{N} 18^{\circ} \mathrm{W}$.

[10] The QBO data used in this article are taken from the 14-level, high-resolution merged data set available from the Max Planck Institute for Meteorology, Hamburg (http:// www.pa.op.dlr.de/CCMVal/Forcings/qbo_data_ccmval) between 1953 and 2004.

\section{Results}

[11] The raw and band-passed Halley data are presented in Figure 1. The data show a clear seasonal pattern with a peak in the measured variance occurring in late winter in both the zonal $\left(<\mathrm{U}^{\prime}\right\rangle^{2}=35 \pm 9 \mathrm{~m}^{2} \mathrm{~s}^{-2}$ in September $)$ and meridional $\left(<\mathrm{V}^{\prime}\right\rangle^{2}=19 \pm 3 \mathrm{~m}^{2} \mathrm{~s}^{-2}$ in August) components, 

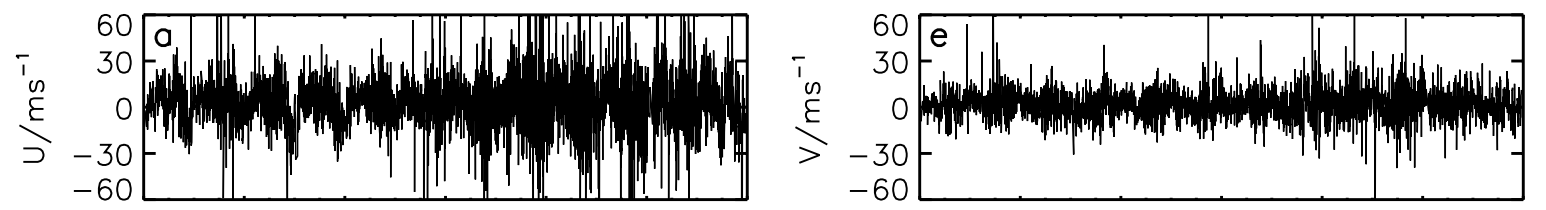

1996199820002002200420062008

1996199820002002200420062008
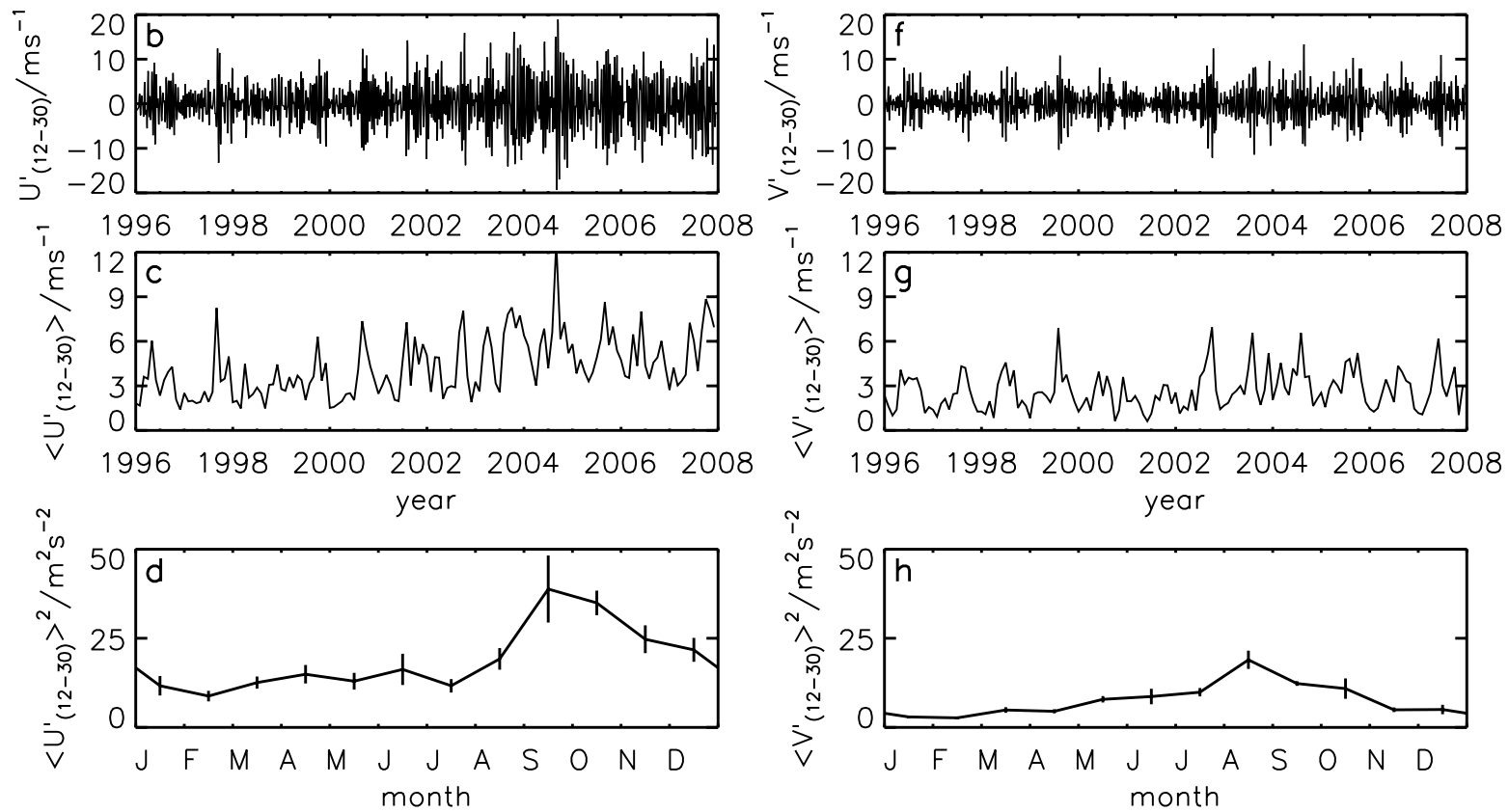

Figure 1. (a) Daily mean zonal meteor winds recorded by the Halley SuperDARN radar between January 1996 and December 2007. (b) Data presented in Figure 1a band-pass filtered between periods of 12 and 30 days. (c) Monthly standard deviation of the data presented in Figure 1b. (d) Monthly mean climatology of the variance of the data presented in Figure 1b. $(e-h)$ As in Figures 1a-1d, but for the meridional component of the horizontal wind.

and a smaller, but still significant, variance in the summer and autumn months of December to May $\left(\left\langle\mathrm{U}^{\prime}\right\rangle^{2} \approx 12 \pm\right.$ $\left.2 \mathrm{~m}^{2} \mathrm{~s}^{-2},<\mathrm{V}^{\prime}>^{2} \approx 5 \pm 1 \mathrm{~m}^{2} \mathrm{~s}^{-2}\right)$. This seasonal behavior is very similar to the planetary wave climatologies presented by Murphy et al. [2007] for the 8-16 day band-pass filtered horizontal winds recorded with an MF radar at Davis station, Antarctica $\left(69^{\circ} \mathrm{S}, 78^{\circ} \mathrm{E}\right)$. Figure 2 shows a wavelet power spectrum of the filtered data set generated using a Morlet wavelet of wave number 6 . This demonstrates the frequency response within the bandpass window for the meridional and zonal components of the wind both temporally (Figures $2 \mathrm{a}$ and $2 \mathrm{c}$ ) and integrated throughout the whole time series (Figures $2 \mathrm{~b}$ and $2 \mathrm{~d}$ ). The late winter maximum across the range of frequencies can clearly be seen in these plots. The global wavelet shows the variance to be skewed toward the higher-frequency components with a peak at around 15 days in both the zonal and meridional components. The time series show large year-to-year variability, and also some evidence of a rising change or longperiod variability in the wave amplitude; this is particularly evident in the zonal component presented in Figure 1c, which will be discussed elsewhere. Here we focus on the role of the equatorial quasi-biennial oscillation in driving the interannual variability of the planetary wavefield in the Antarctic upper mesosphere.
[12] Figure 3 shows climatologies of the monthly mean total variance $\left.\left.\left(<\mathrm{U}^{\prime}\right\rangle^{2}+<\mathrm{V}^{\prime}\right\rangle^{2}\right)$ generated from all the data compared with those generated from the data recorded when the QBO was either in its positive (westerly) or negative (easterly) phase. The QBO has negatively sloping phase fronts throughout the stratosphere, so the timing of the QBO easterly and westerly phases changes with QBO pressure level. The climatologies are plotted for QBO pressure levels between $10 \mathrm{hPa}$ and $70 \mathrm{hPa}$, and the downward progressing signal of the equatorial stratospheric QBO results in a positive correlation with a given parameter at one pressure level being equivalent to a negative correlation at another. See for example Hibbins et al. [2007] who show the altitude profile of the correlation between the QBO and the semidiurnal tidal amplitude above Halley with a peak negative correlation at $35 \mathrm{hPa}$ and peak positive correlation at $5 \mathrm{hPa}$.

[13] It can be seen that the late winter maximum in longperiod planetary wave activity is strongly dependent on the phase of the QBO. When the QBO in the middle stratosphere $(10-20 \mathrm{hPa})$ is easterly the late winter maximum is much stronger than when the QBO is westerly. The effect reverses at a pressure level between 20 and $25 \mathrm{hPa}$ so that the opposite case applies when the data are divided into different QBO phases from the lower stratosphere, i.e., the later winter planetary wave maximum is much stronger when the QBO is in its westerly phase. The step change 

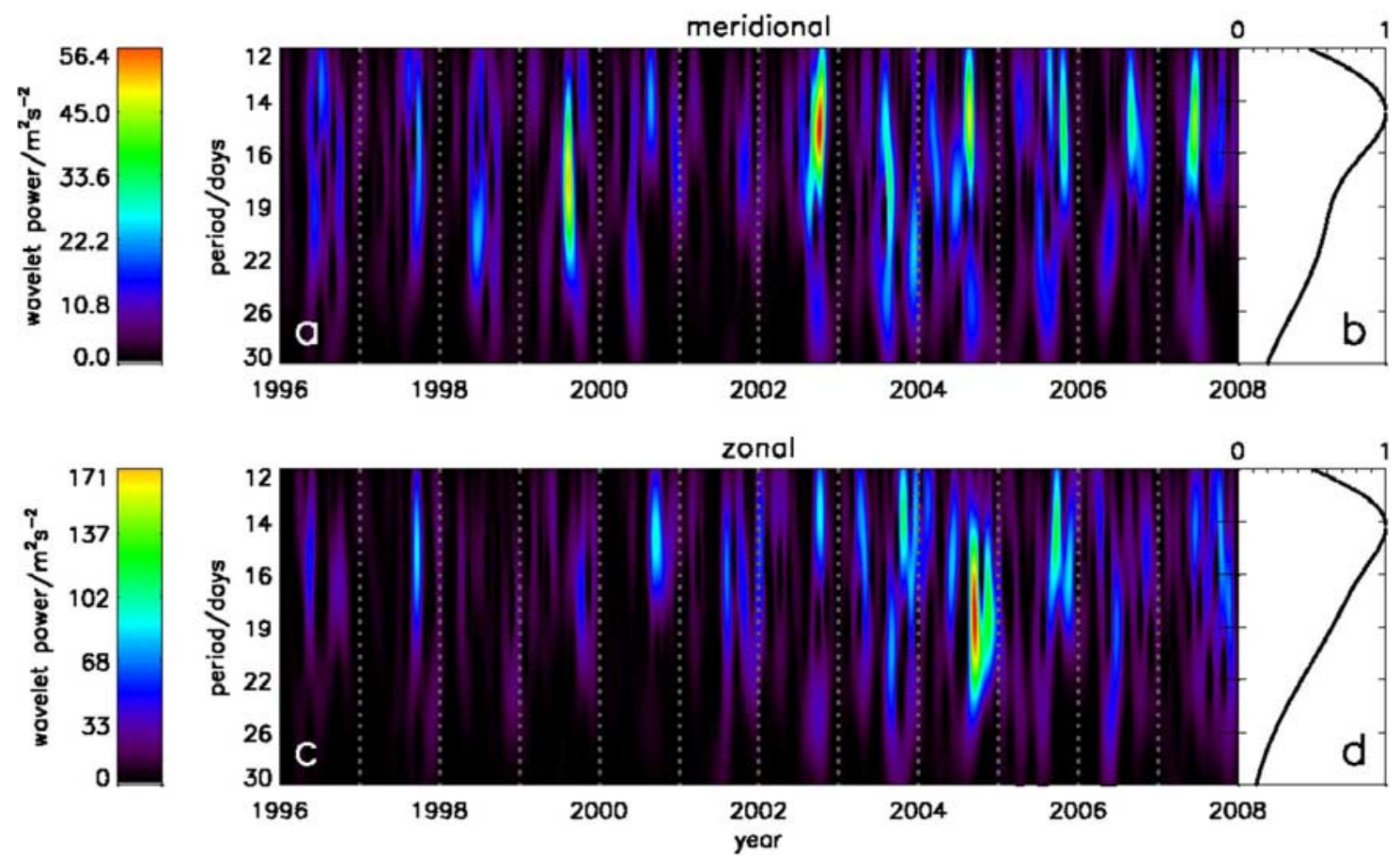

Figure 2. Wavelet power spectrum of the 12-30 day band-passed wind data generated using a Morlet wavelet of wave number 6 : $(\mathrm{a}, \mathrm{c})$ time series for the meridional and zonal component, respectively; (b, d) the normalized integrated wavelet power across the entire time series for the meridional and zonal components, respectively.

in the late winter QBO-dependent climatologies generated from the pressure levels at 20 and $25 \mathrm{hPa}$ is largely due to the peak in the zonal planetary wave activity in the late winter of 2004 (see Figure 1c) switching QBO phases between these two pressure levels. However, repeating the analyses with the 2004 data excluded generates qualitatively similar results to those presented here. A similar dependence is seen in the data recorded during the Austral summer months (December-February). Above about $25 \mathrm{hPa}$ the summertime long-period planetary wave activity in the Antarctic upper mesosphere is stronger when the QBO is in its positive phase. The effect reverses around $30 \mathrm{hPa}$ and the summertime planetary wave activity increases when the QBO in the lower stratosphere is negative or easterly. Overall, dividing the data into QBO positive and negative phases is seen to "flatten" the seasonal variability in the planetary wave amplitudes when the QBO is either positive in the upper stratosphere or negative in the lower stratosphere, and enhance the seasonal differences when the QBO is in the opposite phase.

[14] To emphasize this effect Figure 4 shows the difference in the QBO-phase-dependent climatologies generated in summer (December-February) and late winter (AugustOctober) plotted as a function of QBO pressure level. The error bars represent the standard deviation of 1000 simulations when the months are randomly assigned a positive or negative QBO phase. In the absence of a significant QBO effect on the planetary wave amplitudes these differences would be equal to zero to within the error bars included on the plots. Comparing Figure 4 with Figure 3 shows that the phase of the QBO can change the total variance in the
12-30 day passband by as much as a factor of 2 in both the summer and late winter Antarctic upper mesosphere.

\section{Discussion}

\subsection{Seasonal Variability of Planetary Wave Activity}

[15] The results presented in Figures 3 and 4 show how the QBO can influence the seasonal behavior of long-period planetary wave activity observed in the Antarctic upper mesosphere. Here we divide the zonal monthly mean wind observed by the Halley SuperDARN radar into phases of the $\mathrm{QBO}$, as presented above for the planetary waves, to see how this variability influences the zonal mean circulation in the Antarctic upper mesosphere. Figure 5 shows the difference in the mean zonal wind recorded in August to October separated into westerly and easterly phases of the QBO plotted as a function of QBO pressure level with error bars generated as in Figure 4. No significant difference is seen between the late winter zonal wind climatologies generated during different phases of the QBO when measured between 25 and $12 \mathrm{hPa}$. However, comparison with Figure 4 shows that a westerly QBO (as measured in the lower stratosphere) is associated with an enhancement in the late-winter planetary wave activity in the Antarctic upper mesosphere and a corresponding decrease in the strength of the mean late winter zonal wind by up to $2( \pm 1) \mathrm{ms}^{-1}$. The late-winter mean zonal wind in the upper mesosphere above Halley is around $+6 \mathrm{~ms}^{-1}$ [Hibbins et al., 2006]. One possible suggestion for this is that the QBO-driven enhancement in the planetary wavefield could act as a brake on the eastward zonal mean winds in the Antarctic upper mesosphere either directly or through a modulation of the generation and/or 

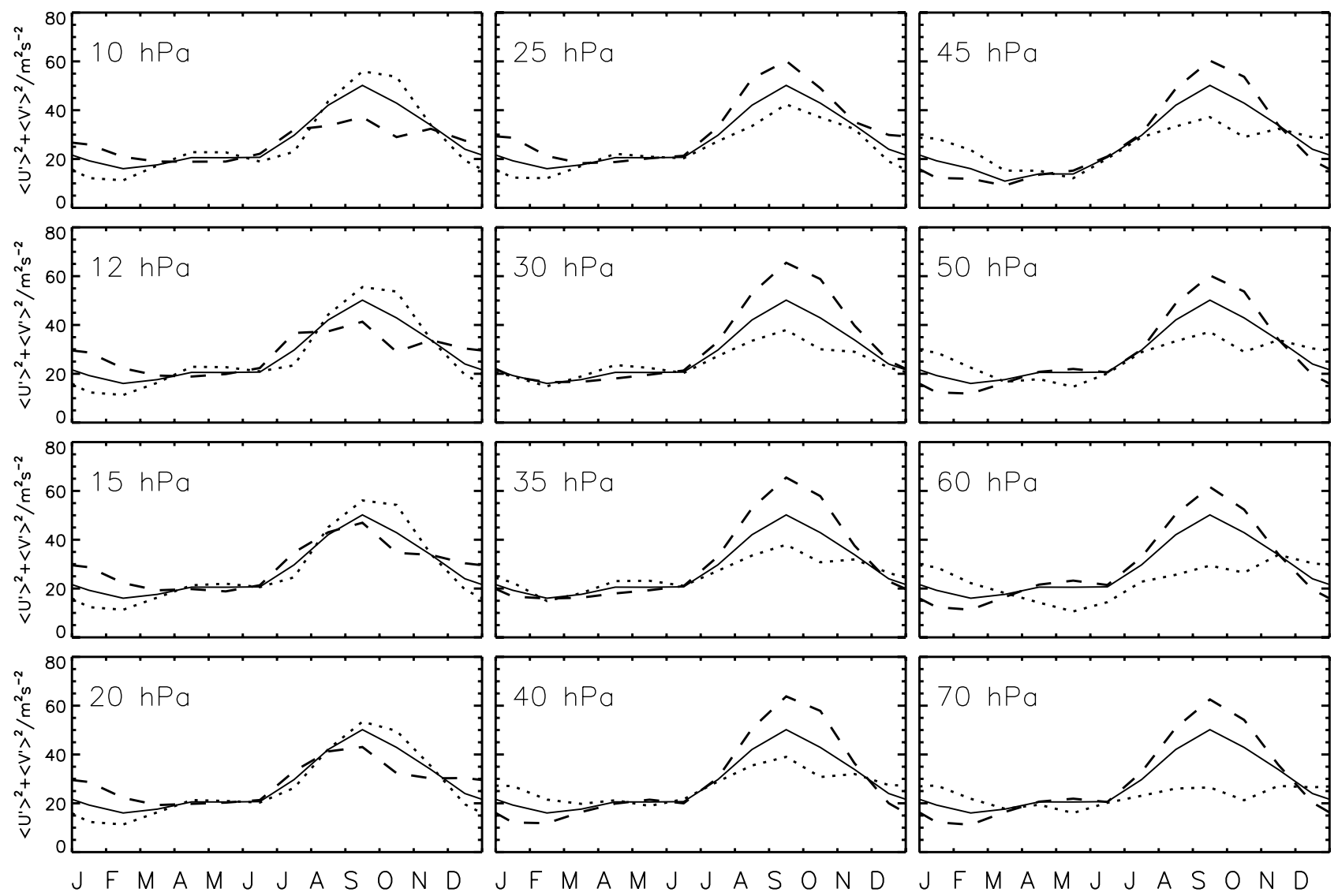

Figure 3. Climatologies of the monthly mean total variance of the Halley zonal and meridional SuperDARN planetary wave activity in the 12-30 day passband (solid line). The dotted and dashed lines represent the equivalent climatologies generated from data recorded when the quasi-biennial oscillation (QBO) is in either its negative (easterly) or positive (westerly) phase, respectively. Each panel represents a different QBO pressure level from $10 \mathrm{hPa}$ to $70 \mathrm{hPa}$ and is labeled accordingly.

vertical propagation of gravity waves. The effect presented here in the MLT region at $95 \mathrm{~km}$ observationally bears some analogy to the Holton-Tan effect [Holton and Tan, 1980] in the lower stratosphere, whereby the northern polar stratospheric wintertime vortex is less strong, warmer, more disturbed, and more susceptible to sudden stratospheric warmings when the equatorial $\mathrm{QBO}$ at $50 \mathrm{hPa}$ is in its easterly phase. Although Labitzke and van Loon [2000] have shown the Holton-Tan relation is more valid at solar cycle minima, it holds true in a statistical sense across a complete solar cycle.

[16] The phase of the QBO is seen to influence the zero wind line at equatorial latitudes which changes the meridional and vertical propagation of quasi-stationary planetary waves from their source region in the troposphere. Easterly phases of the $50 \mathrm{hPa}$ QBO generate conditions more favorable to the vertical and poleward propagation of these waves, which in turn act to disrupt the vortex, leading to slower zonal winds and increased temperatures. Baldwin and Dunkerton [1998] extended this work to look at QBO influences in the wintertime stratospheric polar vortex in both hemispheres. They found that in the Northern Hemisphere the QBO influence on the wintertime polar vortex was optimized when using the $40 \mathrm{hPa}$ pressure level to define the phase of the QBO, when the QBO at $\sim 40 \mathrm{hPa}$

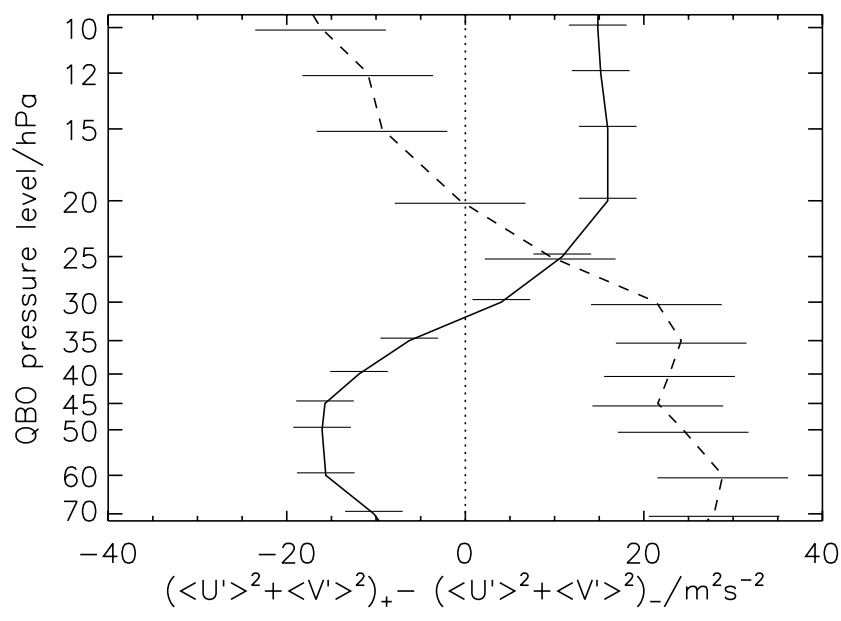

Figure 4. Difference in the total variance of the Halley SuperDARN zonal and meridional winds in the 12-30 day passband separated into positive and negative phases of the QBO. Data are plotted as a function of QBO pressure level. Solid line is data from December, January, and February; dashed line is data from August, September, and October. 


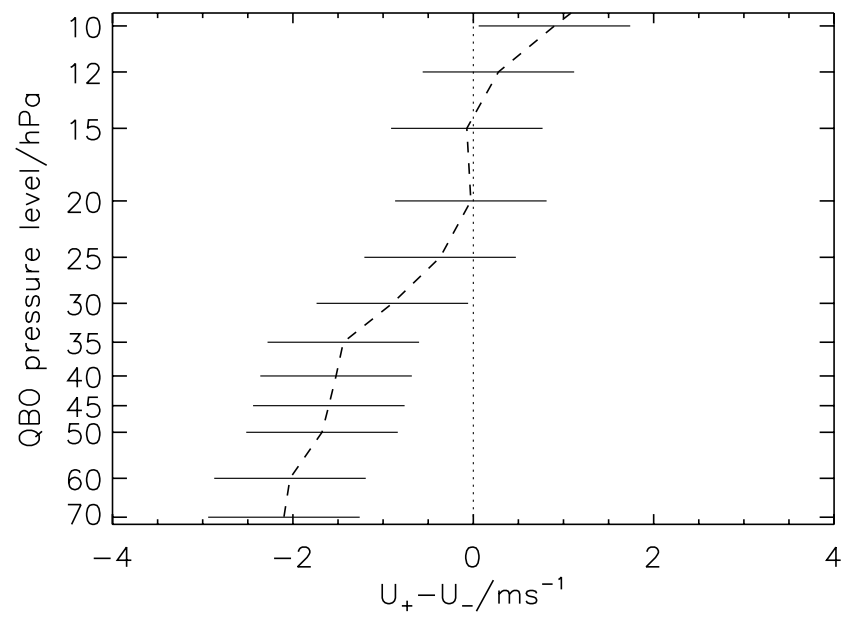

Figure 5. As in Figure 4, but for the Halley SuperDARN zonal mean wind recorded in August, September, and October.

was westerly the northern polar stratospheric vortex was stronger (and vice versa). However, in the Southern Hemisphere they found that a QBO pressure level of $\sim 25 \mathrm{hPa}$ best optimized the differences in the polar vortex and the effect was only observed in the Austral spring time when the vortex had weakened and was beginning to break down. Their analysis showed that at Halley latitudes a westerly (easterly) QBO could increase (decrease) the polar vortex in the upper stratosphere by around $5 \mathrm{~ms}^{-1}$ compared to the long-term average. In the upper mesosphere in later winter, the data presented here show a QBO influence on both the long-period planetary waves and zonal mean wind, which is optimized at a QBO pressure level below $30 \mathrm{hPa}$ or above $10 \mathrm{hPa}$, the significance of which is discussed below.

\subsection{Hemispheric Comparisons}

[17] The interhemispheric propagation of the planetary waves can be either blocked or allowed depending on the QBO-driven wind direction at the equator provided the oscillation is large enough to produce an equatorial wind speed greater than the phase speed of the wave. If this was the case, then when the QBO is in the correct phase to enhance planetary wave activity in the summer hemisphere, a corresponding decrease in planetary wave activity should be observed in the winter hemisphere.

[18] Hibbins et al. [2007] have shown how the QBO can act to enhance the summertime semidiurnal tide in the Antarctic upper mesosphere through a mechanism proposed by Angelats $i$ Coll and Forbes [2002] involving a nonlinear interaction between the migrating semidiurnal tide and quasi-stationary planetary waves. The enhancement was observed to optimise when the phase of the QBO was measured in the upper stratosphere (above $\sim 15 \mathrm{hPa}$ ) where a westerly QBO was associated with an enhancement in the amplitude of the semidiurnal tide in the upper mesosphere. In this article, we have demonstrated that the summertime Antarctic planetary wavefield in the 12-30 day band-pass is also enhanced when the QBO in the upper stratosphere (above $\sim 25 \mathrm{hPa}$ ) is westerly. Espy et al. [1997] used planetary waves derived from $\mathrm{OH}$ rotational temperatures to show that the presence of a 16-day wave in the Northern
Hemisphere high-latitude summer upper mesosphere was dependent on the phase of the equatorial QBO. These data were again optimized at a QBO pressure level in the upper stratosphere $(\sim 10 \mathrm{hPa})$. Espy et al. [1997] concluded that this strongly suggested that the 16-day wave observed in the high-latitude summer mesosphere was generated in the opposite winter hemisphere, as vertical propagation from the troposphere to the mesosphere of long-period westward traveling planetary waves is blocked by the strong westward summer jet in the mesosphere and upper stratosphere [e.g., Charney and Drazin, 1961].

[19] The observations presented here from Halley alone partly support this blocking of the planetary waves by the $\mathrm{QBO}$, in that the QBO dependence on the late winter planetary wave activity is in the opposite sense to that seen in the summertime (i.e., when the QBO is westerly in the upper stratosphere the summertime planetary wavefield is enhanced, and the wintertime planetary wavefield is depleted). To further investigate this possible mechanism, meteor wind data from the closest conjugate Northern Hemisphere SuperDARN radar situated at Pykkvibær, northern Iceland, were analyzed in exactly the same manner as for the Halley data.

[20] The results showing the QBO dependence on the total variance in the 12-30 day passbands for both radars are shown in Figure 6. Although the magnitude of the planetary wave modulation observed in the Pykkvibær radar is smaller than that observed at Halley (possibly related to its lower geographic latitude) it is clear that when there is an enhancement in the Southern Hemisphere planetary wavefield there is a corresponding decrease in the wave activity seen in the Northern Hemisphere site. The data presented here strongly support the theory that the summertime longperiod planetary wave activity observed in the high-latitude upper mesosphere is, at least in part, generated in the winter hemisphere.

[21] If this is the case it follows that there must be a plausible duct through which long-period planetary waves can propagate, and in addition this duct must be influenced sufficiently strongly by the quasi-biennial oscillation to influence the propagation of these waves from the winter to summer hemisphere.

\subsection{Evidence of Mechanism}

[22] In this section we discuss evidence for the mechanism described above from other data sources, and consider how the sites used here correspond with the global picture. Forbes et al. [1995] demonstrated that a ducting channel exists in the weak westerlies of the mesopause region for the interhemispheric propagation of the quasi-16-day planetary wave, though they note that this ducting may be impeded by gravity wave stress. Jiang et al. [2005] compared the 16-day wave in the MLT from nearly 2 years of meteor radar data from Wuhan $\left(31^{\circ} \mathrm{N}, 115^{\circ} \mathrm{E}\right)$ and $\mathrm{MF}$ radar data from Adelaide $\left(35^{\circ} \mathrm{S}, 138^{\circ} \mathrm{E}\right)$. They saw much stronger summertime wave activity at Wuhan during 2002 than 2003 around the mesopause, suggesting that the summertime wave activity at Wuhan originated in the winter Southern Hemisphere. Miyoshi [1999] used a global circulation model to investigate the nature of the 16-day wave. He reported that in the upper mesosphere, the 16-day wave is present not only in the winter hemisphere but also in the summer hemisphere, 

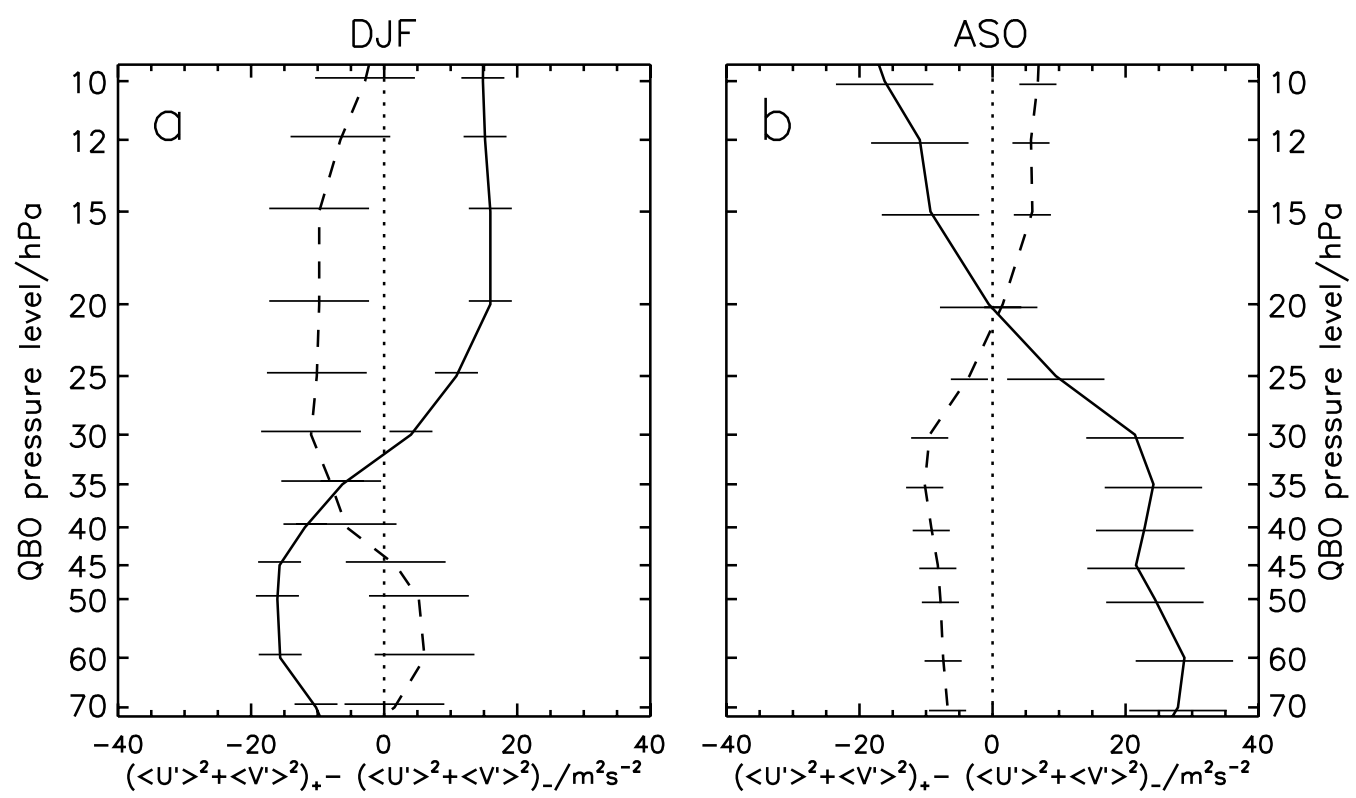

Figure 6. (a) As in Figure 4, but plotted for Halley (solid line) and Pykkvibær (dashed line) SuperDARN total zonal and meridional variance in the 12-30 day passband recorded in December, January, and February. (b) As in Figure 6a, but for data recorded in August, September, and October.

and that the penetration of the 16-day wave from the winter to summer hemisphere occurs near the mesopause region. Isoda et al. [2002] observed an enhancement to the 16-day wave at Yamagawa $\left(32^{\circ} \mathrm{N}, 131^{\circ} \mathrm{E}\right)$ during summer 1996 from MF radar data coincident with a similar enhancement observed at the sites Christmas Island $\left(2^{\circ} \mathrm{N} 157^{\circ} \mathrm{W}\right)$ and Pontianak $\left(0^{\circ} \mathrm{N}, 109^{\circ} \mathrm{E}\right)$. This enhancement was interpreted as evidence for the interhemispheric penetration of the 16-day wave through a region of weak eastward mean zonal wind over the tropical MLT.

[23] In addition, Luo et al. [2002b] used multiple MF radars, located from the Arctic to equator at Tromsø $\left(70^{\circ} \mathrm{N}, 19^{\circ} \mathrm{E}\right)$, Saskatoon $\left(52^{\circ} \mathrm{N}, 107^{\circ} \mathrm{W}\right)$, London, Canada $\left(43^{\circ} \mathrm{N}, 81^{\circ} \mathrm{W}\right)$, Hawaii $\left(21^{\circ} \mathrm{N}, 157^{\circ} \mathrm{W}\right)$, and Christmas Island $\left(2^{\circ} \mathrm{N}, 157^{\circ} \mathrm{W}\right)$, respectively, to study the global extent of planetary-scale 16-day waves. The variability of the wave amplitudes, periods and phases were derived for simultaneous observations between 1993 and 1994. They concluded that the summer wave activity was enhanced when the interhemispheric wave ducts allowed for the leakage of the 16-day wave from the winter hemisphere.

[24] It is clear that there is significant evidence presented both here and elsewhere from modeling and observational studies that long-period planetary waves can indeed duct through the weak eastward wind present in the equatorial upper mesosphere. Observations of the long-term variability of the equatorial mesosphere have been presented by Burrage et al. [1996] who used the high-resolution Doppler imager (HRDI) aboard the Upper Atmosphere Research Satellite (UARS) data and complementary MF radar data from Christmas Island $\left(2^{\circ} \mathrm{N}, 130^{\circ} \mathrm{W}\right)$. They were able to show that the stratospheric QBO extends up to mesospheric heights in a latitude band extending to $\pm 30^{\circ}$ about the equator. This mesospheric QBO is $180^{\circ}$ out of phase with the equatorial $\mathrm{QBO}$ as measured in the lower stratosphere around $40 \mathrm{hPa}$ (and, hence, it is in phase with the QBO in the upper stratosphere). Mayr et al. [1997] subsequently demonstrated how a QBO in the mesosphere could be generated by selective critical-layer absorption or filtering of gravity waves by the underlying winds in the stratosphere together with complementary wave breaking at higher levels in the upper mesosphere. In addition, Sridharan et al. [2003] have compared MF radar horizontal wind data from Tirunelveli $\left(9^{\circ} \mathrm{N}, 78^{\circ} \mathrm{E}\right)$ recorded between 1993 and 2001 with the phase of the equatorial stratospheric QBO. They observe a mesospheric QBO which is out of phase with the QBO in the lower stratosphere between 1993 and 1998; although this anticorrelation appears weaker during 1999-2001, they note that the percentage data acceptance is reduced for their MF radar data recorded after 1998. All these accounts are in agreement with the results, of ducting of planetary waves by the QBO, found from Figures 4 and 5, as discussed above.

[25] The features of equatorial mesospheric intra and interannual variability are summarized by Baldwin et al. [2001]. A mesospheric semiannual oscillation peaks around $80 \mathrm{~km}$ altitude with a maximum amplitude of around $30 \mathrm{~ms}^{-1}$ and falls off rapidly with height above $\sim 90 \mathrm{~km}$. The winds are maximum westward around the equinoxes and eastward around the solstices. In addition an annual component with a maximum amplitude of around $15 \mathrm{~ms}^{-1}$ at $80 \mathrm{~km}$ changes much less rapidly with height and is still above around $10 \mathrm{~ms}^{-1}$ between 60 and $95 \mathrm{~km}$ altitude. Finally a mesospheric QBO, with a maximum amplitude slightly less than that of the semiannual oscillation, peaks at around $90 \mathrm{~km}$ altitude with a vertical full width at half maximum of around $20 \mathrm{~km}$. At $90-95 \mathrm{~km}$ this is the dominant long-period oscillation in the zonal wind of the equatorial mesosphere, exceeding the annual oscillation by a factor of $2-3$, and is of a similar magnitude to the zonal phase speed of a 16-day $\mathrm{s}=1$ planetary wave at the equator $\left(-29 \mathrm{~ms}^{-1}\right)$. Thus, the QBO in the zonal winds in the mesosphere appears to be of 
sufficient amplitude to either block or allow the interhemispheric propagation of long-period planetary waves ducted through the equatorial mesosphere through generation of a critical level.

\subsection{Vertical Profile}

[26] The mesospheric QBO has a $180^{\circ}$ phase shift when compared with that of the stratospheric QBO measured at $40 \mathrm{hPa}$ [Baldwin et al., 2001], and therefore the influence of the quasi-biennial modulation on the equatorial mesosphere is to drive the zonal winds in an opposite direction to that in the equatorial lower stratosphere. A reexamination of Figure 4 shows that when the QBO is positive in the lower stratosphere (and hence negative in the mesosphere) the summertime planetary wavefield in the Antarctic upper mesosphere is less than the long-term mean. If the source region for at least some of this wave activity is the winter (northern) hemisphere, and the ducting region is the equatorial mesosphere, then this is consistent with the observations presented here, as the mesospheric QBO acts to block the interhemispheric propagation of the planetary waves.

[27] Similarly, in the Austral winter a negative mesospheric QBO will prevent propagation of planetary waves into the summer (northern) hemisphere and hence increase the degree of observed wave activity in the Antarctic winter upper mesosphere, as demonstrated in Figure 4. These observations are in agreement with the Northern Hemisphere observations of Espy et al. [1997] who observed no 16-day wave activity in the summer upper mesosphere when the QBO above $10 \mathrm{hPa}$ was negative. As there is a phase reversal of the stratospheric QBO between the upper and lower stratosphere, this corresponds to a negative mesospheric QBO blocking the propagation of planetary waves from the winter to summer hemisphere.

[28] Figure 6 shows signatures of planetary waves in the 12-30 day passband in the northern and southern high latitudes, for summer and winter seasons. A link is clearly seen between these data sets: when the mesospheric QBO is positive in December to February, planetary waves can propagate from the winter (north) to summer (south) hemisphere simultaneously reducing the mean wave activity in the north and increasing that observed in the south. In addition to the evidence described above, results derived from meteor winds recorded simultaneously in both the northern and the southern high-latitude upper mesosphere show support for a causative mechanism through which the QBO influences planetary wave propagation.

\section{Summary}

[29] We have demonstrated that the influence of the equatorial quasi-biennial oscillation extends into the polar upper mesosphere, through the interhemispheric propagation of long-period planetary waves and their effect on the mean flow; and discussed the possibility that the ducting region for the interhemispheric propagation of these waves involves the equatorial upper mesosphere. The easily observed QBO in the stratosphere can be used as a proxy for the behavior of the zonal winds in the equatorial upper mesosphere. When the QBO winds in the lower stratosphere are positive the QBO winds in the upper stratosphere and mesosphere are negative and vice versa. Observations show that the mesospheric QBO is of sufficient amplitude to alternately block and allow the ducting of long-period planetary waves from the winter to the summer hemisphere through generation of a critical level.

[30] Further long-term observations from other highlatitude sites, and a better quantification of the degree of interannual variability in the zonal winds of the equatorial upper mesosphere would be helpful in testing the mechanism proposed here. We note in possible support of the interpretation of the results presented here that the welldocumented period of enhanced long-period MLT planetary wave activity that preceded the 2002 Southern Hemisphere sudden stratospheric warming [e.g., Espy et al., 2003, 2005; Dowdy et al., 2004; Murphy et al., 2007] occurred during a winter when the QBO in the equatorial upper stratosphere (and hence the equatorial mesosphere) was in an easterly phase, which would block propagation of planetary waves out of the winter Southern Hemisphere.

[31] Acknowledgments. The authors would like to thank the staff of the Engineering and Data Management Group of the Physical Sciences Division at the British Antarctic Survey for their technical assistance and for the maintenance and operation of the Halley SuperDARN radar over the years, which was developed under funding from the UK Natural Environment Research Council and the U.S. National Science Foundation (grant DPP-8602975). The Pykkvibaer SuperDARN radar is operated by the Radio and Space Plasma Physics Group, University of Leicester, with funding provided by the Science and Technology Facilities Council, UK, and its predecessor research council, the Particle Physics and Astronomy Research Council.

\section{References}

Angelats i Coll, M., and J. M. Forbes (2002), Nonlinear interactions in the upper atmosphere: The $s=1$ and $s=3$ nonmigrating semidiurnal tides, J. Geophys. Res., 107(A8), 1157, doi:10.1029/2001JA900179.

Baldwin, M. P., and T. J. Dunkerton (1998), Quasi-biennial modulation of the Southern Hemisphere stratospheric polar vortex, Geophys. Res. Lett., 25, 3343-3346, doi:10.1029/98GL02445.

Baldwin, M. P., et al. (2001), The quasi-biennial oscillation, Rev. Geophys., 39, 179-229, doi:10.1029/1999RG000073.

Baumgaertner, A. J. G., A. J. McDonald, G. J. Fraser, and G. E. Plank (2005), Long-term observations of mean winds and tides in the upper mesosphere and lower thermosphere above Scott Base, Antarctica, J. Atmos. Sol. Terr. Phys., 67, 1480-1496, doi:10.1016/j.jastp.2005.07.018.

Burrage, M. D., R. A. Vincent, H. G. Mayr, W. R. Skinner, N. F. Arnold, and P. B. Hays (1996), Long-term variability in the equatorial middle atmosphere zonal wind, J. Geophys. Res., 101, 12,847-12,854, doi:10.1029/96JD00575.

Charney, J. G., and P. G. Drazin (1961), Propagation of planetary-scale disturbances from the lower into the upper atmosphere, J. Geophys. Res., 66, 83-109, doi:10.1029/JZ066i001p00083.

Dowdy, A. J., R. A. Vincent, D. J. Murphy, M. Tsutsumi, D. M. Riggin, and M. J. Jarvis (2004), The large-scale dynamics of the mesosphere-lower thermosphere during the Southern Hemisphere stratospheric warming of 2002, Geophys. Res. Lett., 31, L14102, doi:10.1029/2004GL020282.

Espy, P. J., J. Stegman, and G. Witt (1997), Interannual variations of the quasi-16-day oscillation in the polar summer mesospheric temperature, J. Geophys. Res., 102, 1983-1990, doi:10.1029/96JD02717.

Espy, P. J., R. E. Hibbins, G. O. L. Jones, D. M. Riggin, and D. C. Fritts (2003), Rapid, large-scale temperature changes in the polar mesosphere and their relationship to meridional flows, Geophys. Res. Lett., 30(5), 1240, doi:10.1029/2002GL016452.

Espy, P. J., R. E. Hibbins, D. M. Riggin, and D. C. Fritts (2005), Mesospheric planetary waves over Antarctica during 2002, Geophys. Res. Lett., 32, L21804, doi:10.1029/2005GL023886.

Forbes, J. M., M. E. Hagan, S. Miyahara, F. Vial, A. H. Manson, C. E. Meek, and Y. I. Portnyagin (1995), Quasi 16-day oscillation in the mesosphere and lower thermosphere, J. Geophys. Res., 100, 9149-9163, doi:10.1029/94JD02157.

Greenwald, R. A., K. B. Baker, R. A. Hutchines, and C. Hanuise (1985), An HF phased-array radar for studying small-scale structure in the high latitude ionosphere, Radio Sci., 20, 63-79, doi:10.1029/ RS020i001p00063. 
Greenwald, R. A., et al. (1995), DARN/SuperDARN: A global view of the dynamics of high latitude convection, Space Sci. Rev., 71, 761-796, doi:10.1007/BF00751350.

Hall, G. E., J. W. MacDougall, D. R. Moorcroft, J.-P. St.-Maurice, A. H. Manson, and C. E. Meek (1997), Super Dual Auroral Radar Network observations of meteor echoes, J. Geophys. Res., 102, 14,603-14,614, doi:10.1029/97JA00517.

Hibbins, R. E., and M. J. Jarvis (2008), A long-term comparison of wind and tide measurements in the upper mesosphere recorded with an imaging Doppler interferometer and SuperDARN radar at Halley, Antarctica, Atmos. Chem. Phys., 8, 1367-1376.

Hibbins, R. E., P. J. Espy, and M. J. Jarvis (2006), Mean winds and tides in the mesosphere and lower thermosphere above Halley, Antarctica, J. Atmos. Sol. Terr. Phys., 68, 436-444, doi:10.1016/j.jastp.2005.02.030.

Hibbins, R. E., P. J. Espy, and M. J. Jarvis (2007), Quasi-biennial modulation of the semidiurnal tide in the upper mesosphere above Halley, Antarctica, Geophys. Res. Lett., 34, L21804, doi:10.1029/2007GL031282.

Hocking, W. K., B. Fuller, and B. Vandepeer (2001), Real-time determination of meteor-related parameters utilizing modern digital technology, J. Atmos. Sol. Terr. Phys., 63, 155-169, doi:10.1016/S1364-6826(00) 00138-3.

Holton, J. R., and H.-C. Tan (1980), The influence of the equatorial quasibiennial oscillation on the global circulation at $50 \mathrm{mb}$, J. Atmos. Sci., 37, 2200-2208, doi:10.1175/1520-0469(1980)037<2200: TIOTEQ>2.0. $\mathrm{CO} ; 2$.

Höppner, K., and M. Bittner (2007), Evidence for solar signals in the mesopause temperature variability?, J. Atmos. Sol. Terr. Phys., 69 431 -448, doi:10.1016/j.jastp.2006.10.007.

Hussey, G. C., C. E. Meek, D. André, A. H. Manson, G. J. Sofko, and C. M. Hall (2000), A comparison of Northern Hemisphere winds using SuperDARN meteor trail and MF radar wind measurements, J. Geophys. Res., 105, 18,053-18,066, doi:10.1029/2000JD900272.

Isoda, F., T. Tsuda, T. Nakamura, Y. Murayama, K. Igarashi, R. A. Vincent, I. M. Reid, A. Nuryanto, and S. L. Manurung (2002), Long-period wind oscillations in the mesosphere and lower thermosphere at Yamagawa $\left(32^{\circ} \mathrm{N} ; 131^{\circ} \mathrm{E}\right)$, Pontianak $\left(0^{\circ} \mathrm{N} ; 109^{\circ} \mathrm{E}\right)$ and Christmas Island $\left(2^{\circ} \mathrm{N}\right.$; $\left.157^{\circ} \mathrm{W}\right)$, J. Atmos. Sol. Terr. Phys., 64, 1055-1067, doi:10.1016/S13646826(02)00057-3.

Jacobi, C., R. Schminder, and D. Kurschner (1998), Planetary wave activity obtained from long-period $(2-18$ days) variations of mesopause region winds over Central Europe $\left(52^{\circ} \mathrm{N}, 15^{\circ} \mathrm{E}\right)$, J. Atmos. Sol. Terr. Phys., 60 , 81-93, doi:10.1016/S1364-6826(97)00117-X.

Jacobi, C., K. Fröhlich, C. Viehweg, G. Stober, and D. Kürschnerl (2007), Midlatitude mesosphere/lower thermosphere meridional winds and temperatures measured with meteor radar, Adv. Space Res., 39, 1278-1283, doi:10.1016/j.asr.2007.01.003.

Jarvis, M. J. (1996), Quasi-biennial oscillation effects in the semidiurnal tide of the Antarctic lower thermosphere, Geophys. Res. Lett., 23, $2661-$ 2664, doi:10.1029/96GL02394.

Jarvis, M. J. (1997), Latitudinal variation of quasi-biennial oscillation modulation of the semidiurnal tide in the lower thermosphere, J. Geophys. Res., 102, 27,177-27,187, doi:10.1029/97JA02034.

Jenkins, B., and M. J. Jarvis (1999), Mesospheric winds derived from SuperDARN HF radar meteor echoes at Halley, Antarctica, Earth Planets Space, 51, 685-689.

Jiang, G., J.-G. Xiong, W.-X. Wan, B.-Q. Ning, L.-B. Liu, R. A. Vincent, and I. M. Reid (2005), The 16-day waves in the mesosphere and lowe thermosphere over Wuhan $\left(30.6^{\circ} \mathrm{N}, 114.5^{\circ} \mathrm{E}\right)$ and Adelaide $\left(35^{\circ} \mathrm{S}\right.$, $\left.138^{\circ} \mathrm{E}\right)$, Adv. Space Res., 35, 2005-2010, doi:10.1016/j.asr.2005.03.011.

Jones, G. O. L., K. Charles, and M. J. Jarvis (1997), First mesospheric observations using an imaging Doppler interferometer adaptation of the Dynasonde at Halley, Antarctica, Radio Sci., 32, 2109-2122, doi:10.1029/ 97RS01825.

Labitzke, K., and H. van Loon (2000), The QBO effect on the solar signal in the global stratosphere in the winter of the Northern Hemisphere,
J. Atmos. Sol. Terr. Phys., 62, 621-628, doi:10.1016/S1364-6826(00) 00047-X.

Luo, Y., A. H. Manson, C. E. Meek, C. K. Meyer, and J. M. Forbes (2000), Quasi 16-day oscillations in the mesosphere and lower thermosphere at Saskatoon $\left(52^{\circ} \mathrm{N}, 107^{\circ} \mathrm{W}\right), 1980-1996, J$. Geophys. Res., 105, $2125-$ 2138, doi:10.1029/1999JD900979.

Luo, Y., A. H. Manson, C. E. Meek, T. Thayaparan, J. MacDougall, and W. K. Hocking (2002a), The 16-day wave in the mesosphere and lower thermosphere: Simultaneous observations at Saskatoon $\left(52^{\circ} \mathrm{N}, 107^{\circ} \mathrm{W}\right)$ and London $\left(43^{\circ} \mathrm{N}, 81^{\circ} \mathrm{W}\right)$, Canada, J. Atmos. Sol. Terr. Phys., 64, 1287-1307, doi:10.1016/S1364-6826(02)00042-1.

Luo, Y., et al. (2002b), The 16-day planetary waves: Multi-MF radar observations from the arctic to equator and comparisons with the HRDI measurements and the GSWM modelling results, Ann. Geophys., 20, $691-709$.

Mayr, H. G., J. G. Mengel, C. O. Hines, K. L. Chan, N. F. Arnold, C. A Reddy, and H. S. Porter (1997), The gravity wave Doppler spread theory applied in a numerical spectral model of the middle atmosphere. 2. Equatorial oscillations, J. Geophys. Res., 102, 26,093-26,105, doi:10.1029/ 96JD03214.

Milan, S. E., T. B. Jones, T. R. Robinson, E. C. Thomas, and T. K. Yeoman (1997), Interferometric evidence for the observation of ground backscatter originating behind the CUTLASS coherent HF radars, Ann. Geophys., 15, 29-39, doi:10.1007/s00585-997-0029-y.

Mitchell, N. J., H. R. Middleton, A. G. Beard, P. J. S. Williams, and H. G. Muller (1999), The 16-day planetary wave in the mesosphere and lower thermosphere, Ann. Geophys., 17, 1447-1456, doi:10.1007/s00585-9991447-9.

Miyoshi, Y. (1999), Numerical simulation of the 5-day and 16-day waves in the mesopause region, Earth Planets Space, 51, 763-772.

Murphy, D. J., W. J. R. French, and R. A. Vincent (2007), Long period planetary waves in the mesosphere and lower thermosphere above Davis, Antarctica, J. Atmos. Sol. Terr. Phys., 69, 2118-2138, doi:10.1016/j.jastp. 2007.06.008.

Namboothiri, S. P., A. H. Manson, and C. E. Meek (1993), Variations of mean winds and tides in the upper middle atmosphere over a solar-cycle, Saskatoon, Canada, $52^{\circ} \mathrm{N}, 107^{\circ} \mathrm{W}$, J. Atmos. Sol. Terr. Phys., 55, $1325-$ 1334, doi:10.1016/0021-9169(93)90101-4.

Namboothiri, S. P., C. E. Meek, and A. H. Manson (1994), Variations of mean winds and solar tides in the mesosphere and lower thermosphere over time scales ranging from 6 months to $11 \mathrm{yr}$ : Saskatoon, $52^{\circ} \mathrm{N}, 107^{\circ} \mathrm{W}$, J. Atmos. Terr. Phys., 56, 1313-1325, doi:10.1016/ 0021-9169(94)90069-8.

Namboothiri, S. P., T. Tsuda, and T. Nakamura (1999), Interannual variability of mesospheric mean winds observed with the MU radar, J. Atmos. Sol. Terr. Phys., 61, 1111-1122, doi:10.1016/S1364-6826(99)00076-0.

Naujokat, B. (1986), An update of the observed quasi-biennial oscillation of the stratospheric winds over the tropics, J. Atmos. Sci., 43, 1873-1877, doi:10.1175/1520-0469(1986)043<1873:AUOTOQ>2.0.CO;2.

Press, W. H., B. P. Flannery, S. A. Teukolsky, and W. T. Vetterling (1992), Numerical Recipes in C: The Art of Scientific Computing, 2nd ed., Cambridge Univ. Press, New York.

Sridharan, S., S. Gurubaran, and R. Rajaram (2003), QBO influences on the variability of planetary waves in the equatorial mesopause region, Earth Planets Space, 55, 687-696.

Yukimatu, A. S., and M. Tsutsumi (2002), A new SuperDARN meteor wind measurement: Raw time series analysis method and its application to mesopause region dynamics, Geophys. Res. Lett., 29(20), 1981, doi:10.1029/ 2002 GL015210.

E. A. K. Ford, R. E. Hibbins, and M. J. Jarvis, Physical Sciences Division, British Antarctic Survey, Cambridge CB3 0ET, UK. (rehi@bas. ac.uk) 